\title{
Discussion of the Theory-practice Integration Teaching Reform of Oral Medicine
}

\author{
WANG Chun-feng \\ The Clinical Department in Huaihua Medical College \\ Huaihua, China \\ E-mail: wchf1723@126.com
}

\author{
ZHAO Guang-ye \\ The Clinical Department in Huaihua Medical College \\ Huaihua, China \\ E-mail: $2465466897 @ q q . c o m$
}

\author{
Jin-Ling \\ The Clinical Department in Huaihua Medical College \\ Huaihua, China \\ E-mail: 397211057@qq.com
}

\begin{abstract}
Oral medicine is an important clinical subject of stomatology for higher vocational education. This article makes a discussion of the theory-practice integration teaching reform of oral medicine about supporting the teaching outline, lectures/textbooks,perfect teaching condition, a high quality of "Double Teachers" and scientifically effective teaching evaluation system.
\end{abstract}

Keywords-Oral medicine;Theory-practice integration;Teaching reform;Discussion

\section{INTRODUCTION}

Oral medicine is a clinical subject with strong feature of Synthesis,application and practice. By the theory-practice integration teaching ,the teacher not only requires students to have a solid foundation of theoretical knowledge, but also cultivates students 'ability of comprehensive application of knowledge,clinical thinking and clinical practice ${ }^{[1]}$ 。 However, there is seriously disarticulated phenomenon between theory and practice,teaching and learning since the teacher mainly uses the traditional theory for a long time. Applying this teaching method in Oral medicine, Students cannot understand and digest the basic concept,principle and the operation process. According to these phenomena, the author probe into the theory-practice integration teaching reform of oral medicine.

\section{CONSTRUCT THE COMPLETE THE THEORY-PRACTICE INTEGRATION TEACHING SYSTEM}

To implement the theory-practice integration teaching of oral medicine and achieve good teaching effect, there must be a complete teaching system: supporting the teaching outline,lectures/textbooks, perfect teaching condition, a high quality of "Double Teachers", and scientifically effective teaching evaluation system.

\section{A. Compile syllabus and lectures/textbooks according to the requirements for the theory-practice integration teaching}

(1) Compile the syllabus of the theory-practice integration teaching of oral medicine

The syllabus is the teaching program, which should reflect teaching content,knowledge point and time allocation.
For highlighting the practical requirements and making the teaching process based on rule, the syllabus of the theorypractice integration teaching of oral medicine should be distinguished from the general teaching syllabus.

The lectures/textbooks of the theory-practice integration teaching of oral medicine is divided into 4 module such as tooth disease,dental pulp and periodical disease,periodontal disease and oral mucosal disease, 7 tasks and 36 projects according to the modular structure and clinical criteria. Oral medicine consists of 144 hours. Each project has 4 hours using the mode of 2 hours' theory and 2 hours' practice (Table 1).

According to the task and the project, the teacher must arrange course sequence,distribute the teaching hours of the different content to ensure teaching step by step. Through the theory-practice integration teaching, students not only can deepen understanding the theoretical knowledge, but also can use theoretical knowledge to guide the practical operation and solve the practical problems encountered in practice.

(2) Compile the lectures/textbooks of the theory-practice integration teaching of oral medicine

Lectures or textbooks are the basis for the implementation of integrated teaching. According to the teaching objectives and the teaching task of the medical college and the syllabus of the theory-practice integration teaching of oral medicine, compiling with the scientific and practical principles, Paying attention to the practicability and maneuverability, teachers are organized to carry out repeated discussions and Selectively integrate for traditional teaching content and make the appropriate adjustments about the depth and breadth of the content, then taking project as the guide, taking task driving as the main body, taking ability as standard, taking skill training as the main line, compile the lectures /textbooks of the theory-practice integration teaching of oral medicine. Each project or task contains relevant theory and practice and breaks the phenomenon of the disconnection between theory and practice and the relatively concentrated teaching.

1) Related knowledge section The theoretical knowledge related to project or task is reorganized for sufficient degree and we must try to make it from the theoretical teaching material. 
2) Skills section Skill section must be emphasized the training of basic skills, outstanding operating essentials and difficulties, and strive to enhance the students' practical ability

In the process of theory and practice integration, the design of teaching task should comply with the following principles: first, the theoretical and practical knowledge is integrated closely around the task; second, in the setting of appropriate project, the theoretical background must be progressive in a certain way;

Table 1 curriculum schedule ( 4 hours / project, a total of 144 hours)

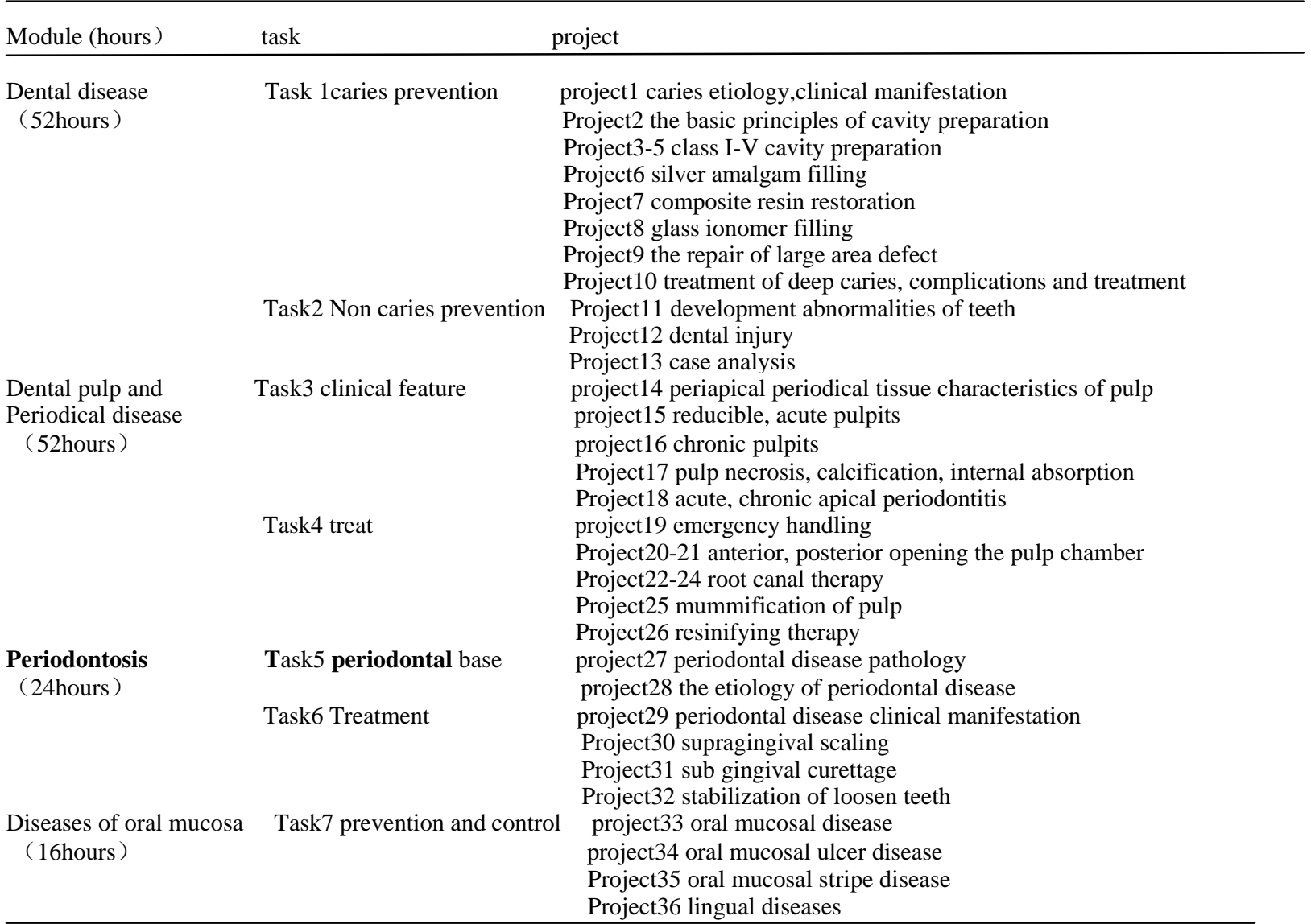

third, every project should not be need for too much theoretical knowledge and cause the teaching organization more difficult; fourth, a project shouldn't be expected to involve all issues of the ability training, So each project should have emphasis. While teaching,learning and doing, both teachers and students construct the quality and skill training framework, enrich the classroom teaching and practice teaching, improve teaching quality.

B. Strengthen practice teaching environment construction; construct the support platform of the of theory-practice integration teaching.

A good teaching environment is the material guarantee of implementation the theory-practice Integration teaching. An important feature of the theory-practice integration teaching is the same space and time, what put forward a very high request on the theory-practice Integration teaching sites which meet both the theory teaching and the practice teaching, and what also put forward higher requirements on the quantity and quality of equipments. Our Oral medicine training rooms improve the real teaching environment and are suitable for the theory-practice integration teaching for being equipped with a set of multimedia equipment,5 sets of comprehensive oral simulation teaching

Systems,a variety of model specimens and wall charts. In the teaching environment, using these head models,specimens, wall charts and multimedia, teachers can emphasize knowledge essentials and difficulties, and realize the organic combination of theory and experiment, and enhance students' clinical thinking ability and practical ability. Let students to find and solve the problems in practice, which achieve good teaching effect because of both saving the class hours and fully mobilizing the enthusiasm of the students' initiative and creativity ${ }^{[2]}$. 
C. cultivates “Double-quality” teachers with high quality and guide the theory-practice integration teaching

"Double-quality" teachers are the fundamental guarantee of the theory-practice integration teaching ${ }^{[3]}$. In the traditional teaching mode, many teachers are only satisfied with completing the prescribed syllabus and the inculcating theoretical knowledge. Whether the students have accepted ,interested in and digested the theory knowledge, the teacher turned a blind eye, not to mention improving students' clinical thinking ability,practical ability and solving actual problem ability. However, In the theory-practice integration teaching mode, the teaching focus have become from teaching to learning and doing,from learning to how to learn and do;Students also have become from passive listeners and the recipients to positive thinkers,explorers and participants. The teacher plays a decisive role in the theorypractice integration teaching process, how to create a good environment of the theory-practice integration teaching, how to guide the students from learning to learn and do, how to let students reach the highest realm of autonomous learning in the theory-practice integration from their point of view. In view of the very strong practice of the course, the teachers must be "Double-quality" ones who should have not only a solid theoretical foundation but also rich practical experience and comprehensive analytical ability of the theory-practice integration teaching materials. Each teacher must practice in the oral cavity hospital more than years and receive oral qualification, only in this way, teachers can understand the points of knowledge and find and correct students' incorrect operation and teach students standard operation methods in the practice process, and guarantee the implementation of the theory-practice integration teaching.

\section{Establish scientific teaching evaluation system, correctly evaluate the teaching effect}

Scientific and reasonable teaching evaluation systems play a very positive role in ensuring the teaching quality and promoting teachers' teaching level and constantly urging students to seriously study ${ }^{[4]}$.

(1) Teachers and students evaluate each other

The objects of evaluation include two aspects of teachers' evaluation to students (Tab2) and students' evaluation to teachers (Tab3). The content and method of teachers' evaluation to students in accordance with the requirements of the outline should highlight the practical skills, at the same time, also consider the students' basic theoretical knowledge, and emphasize the cultivation of students' comprehensive quality. Students' total score consisting of theory,practice and interview scores is a evaluation standard for students to learn this course well. In ordinary teaching, it can not only test students on the theoretical knowledge, but also judge students' ability to use the knowledge, ability to find and solve problems, So it makes a more comprehensive and scientific evaluation in urging the students to master the basic knowledge and practical skills. Students' evaluation to teachers should be able to monitor the teachers' teaching process, to ensure scientific teaching according to the requirement of teaching.
Table 2 Teachers' evaluation to students

\begin{tabular}{|c|c|c|c|}
\hline $\begin{array}{l}\text { Assessment content } \\
\text { reason }\end{array}$ & (Percentage) & Score & Losing \\
\hline Basic theoretical knowledge & 40 & & \\
\hline Practical skills Technical essentials & 10 & & \\
\hline Operating steps & 10 & & \\
\hline Action specification & 10 & & \\
\hline Proficiency in experimental apparatus & 5 & & \\
\hline The overall evaluation of the works & 10 & & \\
\hline Finish on time & 5 & & \\
\hline Cooperation, learning attitude & 5 & & \\
\hline Verbal responses & 5 & & \\
\hline Total score & 100 & & \\
\hline
\end{tabular}

(2) A wide range of evaluation subjects

Evaluation subjects include teacher' evaluation,peer' evaluation and students' self evaluation.

(3) Various evaluation forms

1) Assessment mode: a) Speaking: students answer the teacher's questions. b) Written examination: teachers distribute to students advance print good papers, and then students answer and hand over the papers, immediately the teacher read and explain. c) Operational skills test: 3-4 students randomly selected operate and are scored by their teachers and classmates.

2) Unit test and final test: The examination includes theory part and operation part.. All the questions were randomly written on 100 test cards. Students draw a card, for 5 minutes students answer theoretical questions orally, and then do experimental operation according to the whole process of operation; finally the teacher evaluates on the spot and points out the problems.

This evaluation system is conducive to urge teachers for teaching and mobilize the students to actively participate in various teaching activities, and ensure the theory-practice integration teaching comprehensively effective. Table 3 Students' evaluation to teachers

\begin{tabular}{lcc}
\hline Assessment content & $\begin{array}{c}\text { Score } \\
\text { (Percentage) }\end{array}$ & Losing reason \\
\hline Teacher-led,student-centered, practice as the main line & 20 & \\
Advanced teaching methods, teaching platform & 20 & \\
Basic teaching skills, Skilled and Standard teaching & 30 & \\
Good teaching rhythm and active teaching atmosphere & 10 \\
Scientific and rational practice arrangement & 20 \\
And good interaction & 100 \\
Total score & & \\
\hline
\end{tabular}

III. THE SPECIFIC IMPLEMENTATION OF THE THEORYPRACTICE INTEGRATION TEACHING OF ORAL MEDICINE

According to the curriculum characteristics of oral medicine and the research of the theory-practice integration teaching reform for many years, taking the project3(class I cavity preparation ) in the dental disease module as an example, let's talk about the specific teaching design and organization process of the theory-practice integration teaching of oral medicine.

\section{A. Preparation before class}

Teaching time: the second week. The teaching location: oral simulation training room. Teacher: 3. Students: 
random 30 formed a class, 2 people in each group. Teaching activities: student-centered, teacher-led, student can discuss with each other. Teaching method: each task must adopt the model of theory (two hours) and practice (Two hours). Teaching procedure: each project teaching must have a clear task requirement. Every operation process conforms to specifications and occupation standard. Based on practice, the teacher's teaching,demonstration and students' operation are combined.

(1) Teacher preparation: the teacher must prepare lesson plans and courseware put on work clothes,masks and hats, etc.

(2) Students' preparation: students must review the cavity related knowledge, such as Black cavity classification,the concept and position of class I cavity, preview the teacher assigned task and be familiar with the preparation principle,design method and steps of class I cavity.

(3) Equipment preparation: the experimental teacher must prepare class I cavity model, carving knife, ruler, various drill etc.

$B$. The concrete teaching arrangement of preparating Class I cavities

(1) Student group : 30 students were divided into 15 groups, each teacher is responsible for 5 groups.

(2) Each project teaching is a gradual improvement process. and practice is a alternating process of the theory and practice.

in fact the teaching process of the integration of theory while teaching,learning,doing and exchanging ${ }^{[5-6]}$ (Figure 1).

C. The evaluation of teaching effect

(1) Evaluation on students

Carry out a comprehensive evaluation on each student's theory (40 points), practice (55 points), verbal responses (5 points) by self-assessment,peer evaluation and teacher evaluation (Tab4).
Table 4 the score table of students preparation Class I cavity

Knowledge classification evaluation content evaluation type Score lost score

Theoretical knowledge Black classification, Preparation principle operation test 10 Standard action operation test 10 Choice and use equipment operation test 5 Overall evaluation of works operation test 10 Finish on time operation test 5 Cooperation, learning attitude quality test 5 Verbal responses what structure belongs to the resistance form and retention form? Oral test 5

Total score

(2) Students' evaluation to teachers in the theory-practice integration teaching of oral medicine (Table 3).

(3) Comparison of the effects of the theory-practice integration teaching and traditional teaching (Table 5).

$60 \sim 79$ scores are rated as pass, 80 100 scores are rated excellent. Comparison of the 2 class, there was a significant difference $(\mathrm{P}<0.05)$, what illustrates the theorypractice integration teaching has more advantage than traditional teaching methods.

Table 5 the score Comparison of 2 class

\begin{tabular}{lccc}
\hline Class & number of people & pass & excellent \\
\hline The experimental class & 30 & $6(20.0 \%)$ & $24(80.0 \%)$ \\
The traditional class & 32 & $27(84.4 \%)$ & $5(15.6 \%)$ \\
Total & 62 & $33(63.2 \%)$ & $29(46.8 \%)$ \\
\hline
\end{tabular}

\section{SUMMARY}

The strongly practical characteristics of oral medicine determines itself a theory-practice integration course. Therefore, in the teaching of oral medicine, teachers must change the traditional teaching concepts and teaching methods, and strengthen the theory-practice integration teaching in order to let students obtain the greatest knowledge in the limited classroom time and cultivate students' clinical thinking and practical ability and improve students' comprehensive quality of ${ }^{[7]}$.

\section{REFERENCES}

[1] Liu JY. Teaching reform in oral medicine. Health Vocational Education,2010,28(3):58-59.

[2] Liu BF. Discussion on integration of anatomy theory and laboratory teaching Health Vocational Education,2007,27(1):75-76.

[3] Wang JQ. On the updating of higher vocational teachers' teaching idea. Education and Vocation,2007(27):161-162.

[4] Lin Yan-ping, LI Ping, BAI Hai-yan etc. Research and practice of diverse test methods [J]. Researches in Medical Education, 2010,09(9):1249-1251

[5] [TANG Xiao-lu. To Promote Physiological Teaching by Problembased Learning [J]. Researches in Medical Education, 2007,6(7):594595.

[6] Kang HY . The teaching effect of three-in-one combination teaching approach in practice and training course in oral medicine Health Vocational Education,2009,27(7):71-72 


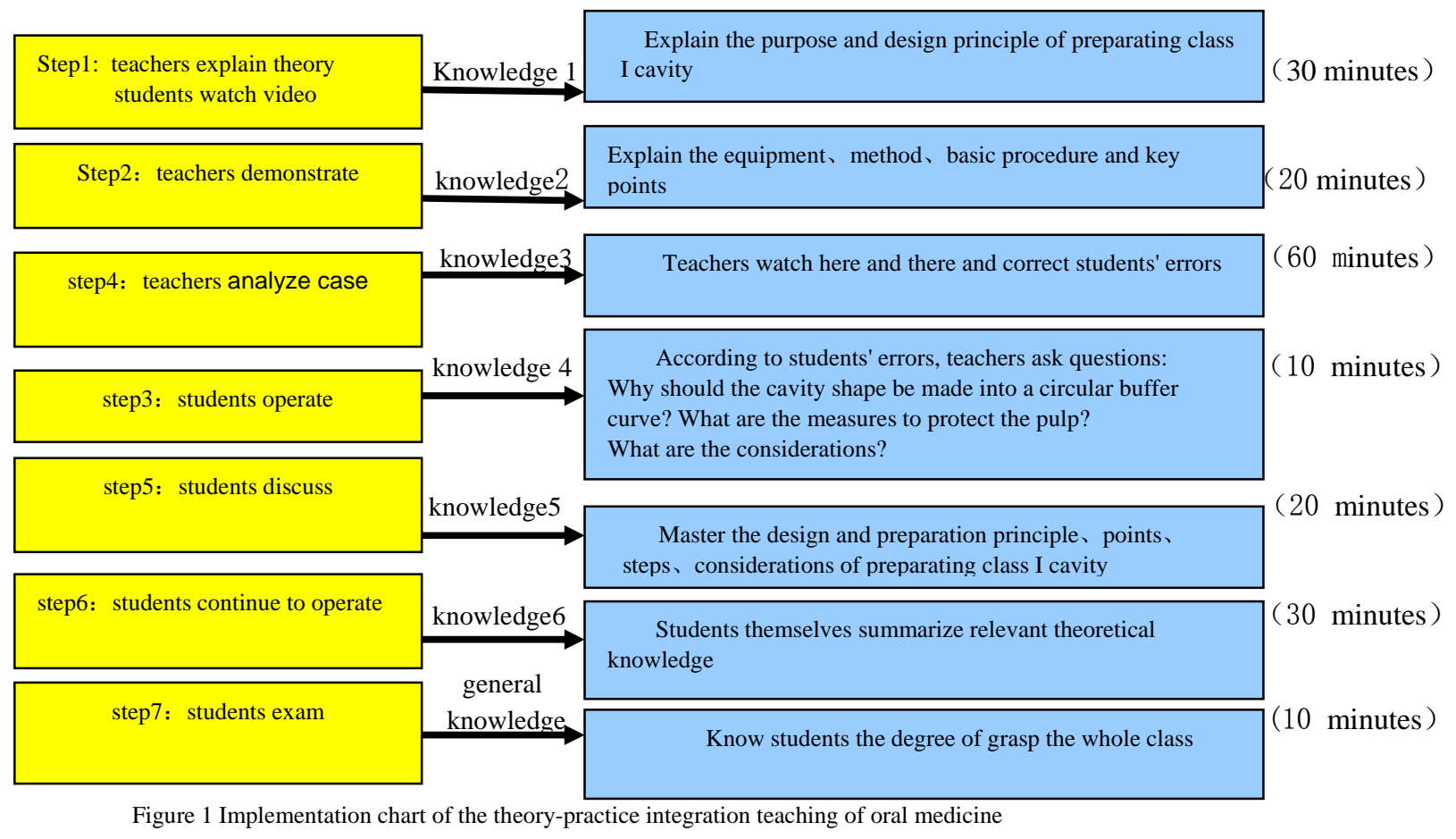

Fund project:

The teaching reform and research project of the Education Department of Hunan province, in 2012. (No. 604)

The teaching reform and research project of Huaihua Medical College. (No. 2010JG05)

Author brief introduction:

Name: WANG Chun-feng.

Date of Birth: February, 1976.

Education: Graduate student.

Research direction: mainly en

Address: The Clinical Department in Huaihua Medical College, Huaihua 418000,China

Cell-phone number: 15115140108
Sex: female.

Place of Birth: Xinshao County, Shaoyang City, Hunan Province in china. Title: Lecturer.

E-mail:wchf1723@126.com 